\title{
Are building users prepared for energy flexible buildings-A large-scale survey in the Netherlands
}

\section{Li, Rongling; Dane, Gamze; Finck, Christian ; Zeiler, Wim}

\section{Published in:}

Applied Energy

Link to article, DOI:

10.1016/j.apenergy.2017.06.067

Publication date:

2017

Document Version

Publisher's PDF, also known as Version of record

Link back to DTU Orbit

Citation (APA):

Li, R., Dane, G., Finck, C., \& Zeiler, W. (2017). Are building users prepared for energy flexible buildings-A large-scale survey in the Netherlands. Applied Energy, 203, 623-634.

https://doi.org/10.1016/j.apenergy.2017.06.067

\section{General rights}

Copyright and moral rights for the publications made accessible in the public portal are retained by the authors and/or other copyright owners and it is a condition of accessing publications that users recognise and abide by the legal requirements associated with these rights.

- Users may download and print one copy of any publication from the public portal for the purpose of private study or research.

- You may not further distribute the material or use it for any profit-making activity or commercial gain

- You may freely distribute the URL identifying the publication in the public portal 


\title{
Are building users prepared for energy flexible buildings?-A large-scale survey in the Netherlands
}

\author{
Rongling Li ${ }^{\mathrm{a}, *}$, Gamze Dane ${ }^{\mathrm{b}}$, Christian Finck ${ }^{\mathrm{c}}$, Wim Zeiler ${ }^{\mathrm{c}}$ \\ a Department of Civil Engineering, Technical University of Denmark, Nils Koppels Allé Building 402, 2800 Kgs. Lyngby, Denmark \\ ${ }^{\mathrm{b}}$ Information Systems in the Built Environment, Department of Built Environment, Eindhoven University of Technology, P.O. Box 513, 5600 MB Eindhoven, The Netherlands \\ ${ }^{\mathrm{c}}$ Building Physics and Services, Department of Built Environment, Eindhoven University of Technology, P.O. Box 513, 5600 MB Eindhoven, The Netherlands
}

\section{H I G H L I G H T S}

- Awareness of smart grids is the highest among respondents aged 20-29 years old.

- Willingness to use smart technologies and change energy behaviour are interdependent.

- Potential flexible building users were found to be $11 \%$ of the respondents.

\section{A R T I C L E I N F O}

\section{Article history:}

Received 20 December 2016

Received in revised form 13 May 2017

Accepted 19 June 2017

\section{Keywords:}

Building occupant

Building energy flexibility

Demand side

Smart technology

Smart grids

Questionnaire

Smart building

\begin{abstract}
A B S T R A C T
Building energy flexibility might play a crucial role in demand side management for integrating intermittent renewables into smart grids. The potential of building energy flexibility depends not only on the physical characteristics of a building but also on occupant behaviour in the building. Building users will have to adopt smart technologies and to change their daily energy use behaviours or routines, if energy flexibility is to be achieved. The willingness of users to make changes will determine how much demand flexibility can be achieved in buildings and whether energy flexible buildings can be realized. This will have a considerable impact on the transition to smart grids. This study is thus to assess the perception of smart grids and energy flexible buildings by building users, and their readiness for them on a large scale. We attempted to identify the key characteristics of the ideal user of flexible buildings. A questionnaire was designed and administered as an online survey in the Netherlands. The questionnaire consisted of questions about the sociodemographic characteristics of the current users, house type, household composition, current energy use behaviour, willingness to use smart technologies, and willingness to change energy use behaviour. The survey was completed by 835 respondents, of which 785 (94\%) were considered to have provided a genuine response. Our analysis showed that the concept of smart grids is an unfamiliar one, as more than $60 \%$ of the respondents had never heard of smart grids. However, unfamiliarity with smart grids increased with age, and half of the respondents aged 20-29 years old were aware of the concept. Monetary incentives were identified as the biggest motivating factor for adoption of smart grid technologies. It was also found that people would be most in favour of acquiring smart dishwashers (65\% of the respondents) and refrigerator/freezers (60\%). Statistical analysis shows that people who are willing to use smart technologies are also willing to change their behaviour, and can thus be categorised as potentially flexible building users. Given certain assumptions, $11 \%$ of the respondents were found to be potentially flexible building users. To encourage people to be prepared for energy flexible buildings, awareness of smart grids will have to be increased, and the adoption of smart technologies may have to be promoted by providing incentives such as financial rewards.
\end{abstract}

(c) 2017 The Author(s). Published by Elsevier Ltd. This is an open access article under the CC BY license (http://creativecommons.org/licenses/by/4.0/).

\section{Introduction}

Smart grids can facilitate flexible electricity consumption, which is crucial for a future where energy demand will have to

\footnotetext{
* Corresponding author.

E-mail address: liron@byg.dtu.dk (R. Li).
}

be in phase with energy generation, due to inevitable fluctuations in the availability of renewable energy $[1,2]$. Buildings account for one-third of total energy consumption in most developed countries, which amounts to considerable potential for activating flexible electricity consumption. Building energy flexibility is related not only to physical building characteristics, but also to building 
users. Unlocking building energy flexibility requires building users to adapt energy use behaviours to the needs of the smart grid $[2,3]$. Willingness to accept these changes determines how much potential flexibility buildings can provide, and thus has a considerable impact on the development of smart grid technology [4].

To date, most of the studies on building energy flexibility have focused on physical characteristics of buildings and have been completed using measurements, modelling, and simulation [513]. Existing research on users has primarily been conducted in community or district scale pilot projects for demonstration smart grid technologies [14-19].

User interaction and user perspective were part of one of the earliest pilot project of demand side management, the Olympic Peninsula Project $[14,15]$. With 112 households participated. At the end of the project, most of the participants (95\%) would have liked to continue using the program due to the positive impact the program had on their electricity usage. This is promising for the development of smart grids, but the findings may not be representative for other districts or regions.

Several other studies on the interaction between users and smart products and services have shown significant impact of users on energy consumption and load management. In general, building automation system can have large impact on building energy performance, as showed by Ippolito et al. [17]. The user impact and user interaction with building control system was further presented by Graditi et al. [18]. Their study showed that the real time electric and thermal control systems can reduce energy consumptions. In the study conducted by Ayodele et al. [20], providing feedback to building residents on the building peak load reduction was shown to be effective in reducing the peak load of buildings.

In these existing studies, user interaction with smart technologies was one of the key testing elements to identify motivating factors for users to adopt smart grid products. However, the relatively small scale of such pilot projects restricts the validity of the results. As the development of smart grid and smart grid technologies is a global issue, a user study on a larger scale is thus essential. Therefore, we developed a questionnaire and conducted a large-scale survey in the Netherlands to gain insights into this issue on a national scale.

In the questionnaire, a list of smart grid related products and services are included because they are expected to influence the daily decisions and routines of users, leading to more flexible electricity demand patterns. According to Geelen et al. [21] and Obinna et al. [22], in a smart grid context, the products and services available to households can be categorized as: micro-generators (e.g. photovoltaic systems), energy storage e.g. domestic hot water tanks and batteries), smart appliances e.g. heat pumps, air conditioners, dishwashers, washing machines, and clothes dryers), smart meters, building energy management systems, and dynamic energy pricing and contracts. The above technologies are included in this study and these technologies are named smart technologies, as used in [16].

Motivating factors are also part of the questionnaire. In most pilot projects in Europe, to get users involved, three motivational factors are commonly used, namely, environmental concerns, reduction of or control over electricity bills, and better comfort [23-25]. Toft et al. [26] reported that the acceptance of smart grid technology depends on perception of the technology as helpful and effortless to use. These factors were therefore also included in our questionnaire.

Kobus et al. [6] stated that the most important factor in motivating and activating users is to provide them with a dynamic price signal. Users then have a monetary incentive to move their electricity consumption to off-peak hours. Dynamic pricing is the key to utilising demand flexibility, and this mechanism has been used in various pilot projects, such as PowerMatcher [27] and Your Energy Moment [16] in the Netherlands, the EcoGrid EU demonstration in Denmark [19] and the Olympic Peninsula Project in the U.S. [28]. A study on the performance of all types of smart white good appliances under dynamic pricing demand response scheme was conducted in a Belgium pilot project, Linear [29] with 58 households participated. A significant shift of flexible electricity consumption to lower price periods was observed. A high variation was also found in the energy consumption and energy flexibility among the project participants. We therefore included dynamic pricing in the present survey to investigate users' perception of it on a large scale.

Unlike previous studies which have focused on community or district, this study aims to give a broader perspective by surveying a large representative sample of all households in the Netherlands. We aimed to understand the influence of individual/household characteristics, dwelling characteristics, household energy consumption, and knowledge and acceptance of smart grid technologies on the willingness of occupants to use smart technologies and change their energy use behaviour. We assessed how well building users are prepared to contribute to the energy flexibility of their buildings. We also investigated building user perceptions of smart grids and their readiness to adopt smart technologies.

The paper is structured as follows: in Section 2 the methods for designing the questionnaire, conducting the survey and analysing data are presented. Section 3 includes two major parts. In Section 3.1, the survey data is presented in figures and tables to give the reader an overview of the results. Section 3.2 presents statistical analyses to identify the characteristics of potential flexible building users. Section 4 concludes the work.

\section{Methodology}

\subsection{Questionnaire design}

The questionnaire consisted of questions about (1) user perceptions of smart grids, smart technologies, their willingness to use smart technologies and change energy use behaviours, and (2) sociodemographic characteristics and current energy use behaviours. These questions are listed in the Appendix.

First, a short description of smart grids was provided, as we assumed that the concept of smart grids would be unfamiliar to the majority of building users. This description was about the concept and working principle of smart grids, and some of their possible influences on the daily lives of users. The text was as follows:

An introduction to smart grids and how they work

There is a mismatch between moments when the largest amount of renewable energy is generated and moments when the maximum energy is consumed. The renewable energy generation is high when the sun shines brightly and the wind blows fast. The energy consumption in our homes occurs after we wake up in the morning and when we are at home in the evening. Our energy consumption should be adjusted to match the renewable energy production to make full use of the available renewable energy. This can be done with smart grids.

In smart grids, your energy consumption can be adjusted according to the renewable energy generation. When the energy generation exceeds the energy demand, the energy price will fall. At this time, you can use your home appliances (e.g., washing machine) and charge batteries cheaply. In contrast, when energy generation is insufficient, the energy price will increase and you will pay more for using your appliances. This energy price will be communicated by your energy suppliers if you have a smart meter installed, which also gives you insights into your energy consumption. Based on this, you can switch your appliances on or off. However, if you have 
appliances that can communicate with smart grids, these actions can be done automatically. Such appliances are called smart appliances.

Next, the survey participants were asked to answer questions about their perception, willingness, and motivation to use smart grid products and services. In these questions, a 5-point Likert scale was used. Finally, the participants were asked for respondent and household characteristics, dwelling characteristics, and current energy usage, including energy bill information and heating habits.

\subsection{Survey and response}

The questionnaire was translated into Dutch and completed by ten Dutch locals with different educational backgrounds. The feedback from them was implemented so that the questionnaire would be easily understood by all test participants. The final version of the questionnaire was used for a large scale survey in July and August 2016 through a professional online survey company. The survey was restricted to subjects who were fully or partly responsible for paying their household energy bills, so the population segment younger than 20 years old was excluded from this survey. The questionnaire link was sent to contacts in the company's database selected by the following interlocked stratification, which was intended to be representative of the Dutch population: gender (female: $50 \%$ and male: $50 \%$, age (20-29 years old: $19 \%, 30-$ 44 years old: $25 \%, 45-59$ years old: $27 \%$, and 60 years old and above: $29 \%$ ), and education level (low: $23 \%$, middle: $48 \%$, and high: 29\%). The online survey was closed when 835 questionnaires had been completed.

\subsection{Data analysis}

The time it took to answer the questionnaire was used as a filter to select effective respondents. This filter is the same as that used in a comparable survey by Toft et al. [26]. In our study, respondents who completed the survey in less than 5 min were excluded from the analysis as they were assumed to have answered arbitrarily. As a result, 785 respondents were classed as reliable and used in the data analysis. For these 785 effective respondents, the average time spent answering the questionnaire was 16 min.

Descriptive analysis was performed to uncover user perceptions of smart grids and their impact on the daily lives of users, which is presented in Section 3.1. Statistical analysis was conducted using the statistical analysis software SPSS to analyse user readiness for energy flexible buildings, which is presented in Section 3.2. Our aim was to understand the influence of individual/household characteristics, dwelling characteristics, household energy consumption, and knowledge and acceptance of smart grid technologies on the willingness of occupants to use smart technologies and change their energy use behaviour. We therefore performed several regression analyses on the dependent variables as measures of willingness to use smart technologies, postpone home appliance start times, turn off the heating or air-conditioning for a short time, and reduce the heating temperature setting. The willingness to use smart technologies and the willingness to postpone the start times of home appliances were analysed using linear regressions. Their willingness to turn off heating or airconditioning for a short time and their willingness to reduce the heating temperature settings were examined using ordinal regressions. The regression analysis type was chosen according to the type of the dependent variables, which will be discussed in Section 3.2. In these analyses, we also used the dependent variable for each estimation as an independent variable in other analyses. In this way, information overlap between the analyses was avoided and any relations between each measure of respondents' acceptance of smart grids could be determined.

\section{Results and discussion}

The group characteristics of the survey respondents are shown in Table 1. The sample was compared with data from the Central Bureau of Statistics in the Netherlands [30] to verify that it is representative of the general population. For the CBS data, the percentage of each age segment was calculated using only the population above 20 years old. The education level of the Dutch population was compiled based on data from the total population aged 15-64 in 2013, which was the latest available. It can be seen that the survey sample was representative of the Dutch population.

\subsection{Descriptive analysis of user perception of smart technologies}

\subsubsection{Familiarity with smart grids and smart technologies}

After providing an introduction to smart grids and their possible influence on the daily lives of users (as explained in Section 2.1), the respondents were asked about their awareness of smart grids prior to the survey. Five options were presented, from "never heard of it" to "know a lot about the concept." As shown in Fig. 1, more than $60 \%$ of the respondents were not previously aware of the concept. The rest of the respondents were aware of the concept, but only a small number of them (less than 5\%) stated that they understood the concept and its consequences.

When we look at familiarity across age groups (as shown in Fig. 2), we found that $48 \%$ of young people (20-29 years old) were already aware of smart grids. The highest degree of awareness was found within the age category $20-29$, followed by $30-44,45-59$, and lastly 60 and above. This may indicate that younger people are more aware of smart grids than older people.

Awareness about each smart technology is shown in Fig. 3. The options for answering this question ranged from "never heard of it" to "I own one." Although the awareness about each individual product or service was different, on average, more than half of the respondents knew about smart technologies, which was higher

Table 1

Sample characteristics $(\mathrm{N}=785)$

\begin{tabular}{lll}
\hline Characteristics & Survey sample & $\begin{array}{l}\text { Dutch population } \\
\text { data source [30] }\end{array}$ \\
\hline Gender & $50.4 \%$ male, 49.6\% female & $49.5 \%$ male, 50.5\% female \\
Age (years old) & $20-40: 32 \%$ & $20-40: 32 \%$ \\
& $40-65: 47 \%$ & $40-65: 45 \%$ \\
& $65^{+}: 20 \%$ & $65^{+}: 23 \%$ \\
Education & Low (primary and secondary): $27 \%$ Low: $28 \%$ \\
level & Middle (senior secondary): $42 \%$ & Middle: $41 \%$ \\
& High (bachelor and higher): $31 \%$ & High: $29 \%$ \\
\hline
\end{tabular}

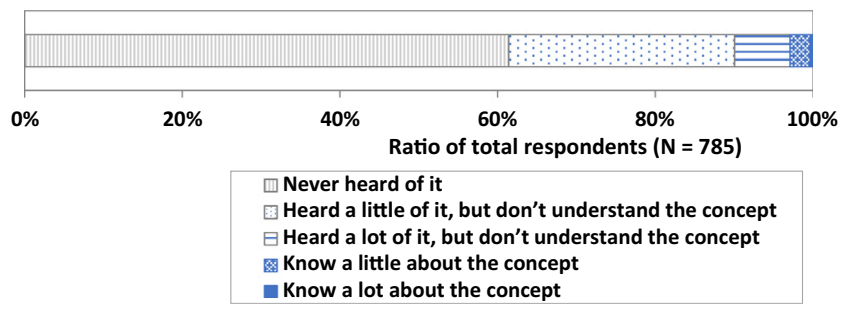

Fig. 1. Familiarity with smart grids. 


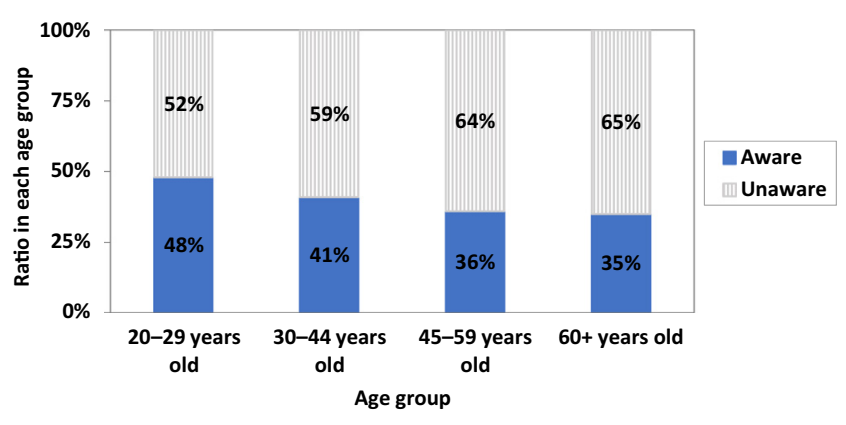

Fig. 2. Awareness of smart grids by age category.

than their awareness about smart grids. The reason for the discrepancy might be that products or services are closer to the daily lives of respondents than power grids. Solar panels (PV), smart meters, and electric vehicles were the top three products that respondents knew about prior to the survey.

\subsubsection{Household energy saving actions and smart technology ownership}

Actions that were reported as already being taken to reduce household energy consumption or to use renewable energy are shown in Fig. 4. It can be seen that some action was taken by about half of the respondent households to save energy or reduce their energy bill. It also shows that energy labelling of appliances is a meaningful way to promote energy efficiency. It could therefore be advantageous to use a similar labelling system for smart technologies to promote renewable energy use. Use of night tariffs to reduce energy bills had been adopted by one-third of the respondents, even though the night tariff was only $10 \% 0.02 € / \mathrm{kWh}$ ) lower than the normal tariff. This result is in line with the statement made by Kobus et al. [6] that by providing a dynamic price signal, users have a monetary incentive to move their electricity consumption to off-peak hours. Although renewable energy generation accounted for only $5.8 \%$ of the Dutch energy generation in 2015 [30], 14\% of the respondents declared that their electricity was generated partly) from renewable energy resources. This

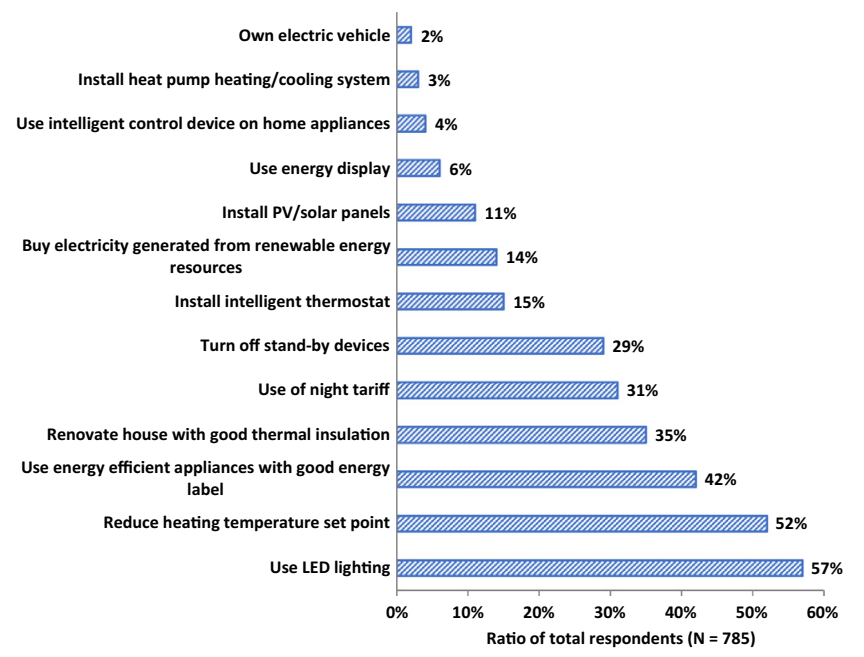

Fig. 4. Actions taken for energy savings and renewable energy usage in respondent households.

indicates that renewable energy is used as a positive aspect in the marketing of electricity. This agrees with a Danish study which also found that people are willing to pay for green energy [31]. All in all, these actions together show a promising future for user acceptance and adoption of smart grids, at least in affluent countries.

Current smart technology ownership in respondent households is shown in Fig. 5. Except for smart meters and solar panels, smart grid related energy systems and services are owned by fewer than $2 \%$ of the respondents. This indicates that smart technologies and smart grid services are still at an early stage in their adoption. During this early adoption stage, user engagement should be encouraged in order to support successful implementation of smart grid technologies [22].

\subsubsection{Willingness to use smart technologies}

Although the ownership of smart technologies was low, respondents stated that they were positive about using smart grid

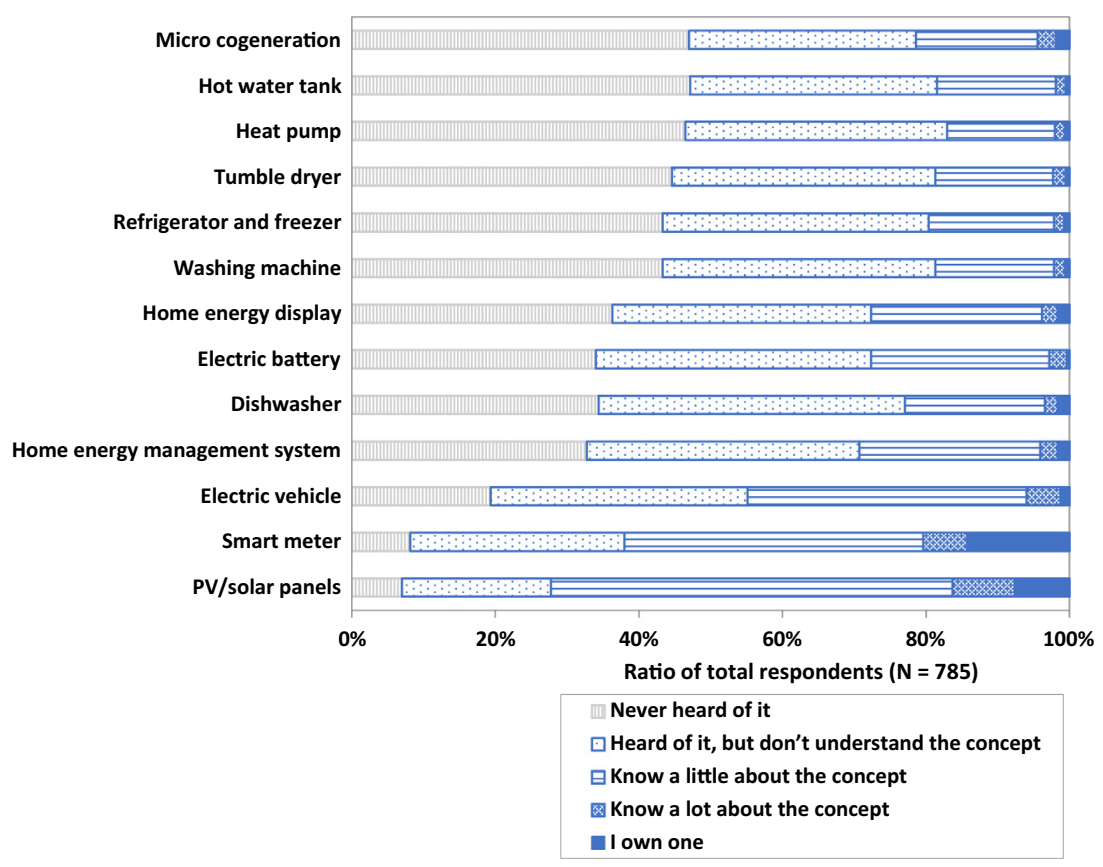

Fig. 3. Familiarity with smart technologies. 


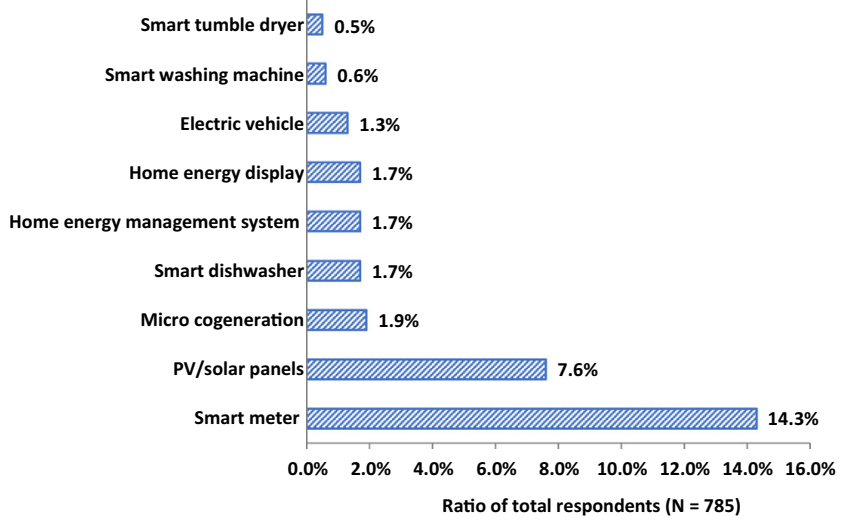

Fig. 5. Ownership of smart technologies.

products and services in the future, as shown in Fig. 6. Among the smart technologies, smart dishwashers and smart refrigerator/ freezers were the most popular, being favoured by $60 \%$ or more of the respondents. However, a willingness to use an electric vehicle with a smart charging and discharging system was the lowest of all. This is a negative finding that was unexpected from the smart grid development scheme published by the International Energy Agency [32], in which electric vehicles were expected to play an important role in the major economies, including the Netherlands. The reasons that respondents were less willing to use an electric vehicle with smart charging and discharging is outside the scope of this study, but it should be investigated further. It seems possible that respondents were reporting their unwillingness to own an electric vehicle, with or without smart charging and discharging, rather than an unwillingness to use.

\subsubsection{Willingness to change energy use behaviour}

Dynamic pricing was included in the survey. The price information was embodied in questions about willingness to change energy use behaviours and to choose a control option.
(1) Postpone the start times of smart appliances

The willingness to postpone the start times of smart appliance is shown in Table 2. The majority of the respondents were willing to postpone the start of a dishwasher, washing machine, or tumble dryer. For these three appliances, the maximum delay was flexible with a substantial amount of respondents choosing any time between $20 \mathrm{~min}$ and $24 \mathrm{~h}$. These results are comparable with real time measurements from the LINEAR pilot [5], in which flexible hours were distributed throughout $24 \mathrm{~h}$, with an average time around eight hours.

The willingness to postpone the use of irons, vacuum cleaners and heating systems, and the charging of electric vehicles, was also relatively high, with more than half of the respondents giving positive answers. Although the flexibility potential of irons and vacuum cleaners has not been a focus in most studies of demand flexibility, they have good potential for providing energy flexibility in Dutch residential buildings. In this study we found that irons and vacuum cleaners are mostly used in the daytime, so they could play an important role in shifting electricity demand during daytime hours. More than half of the respondents were unwilling to postpone the use of an oven, which is mostly used in the evening when there is peak energy demand in residential buildings. This indicates that the energy flexibility potential of ovens is relatively low, as expected.

(2) Turning off heating and air-conditioning systems, and reducing heating temperature settings

The willingness to change energy use behaviour, including turning off heating or air-conditioning for a short time and the willingness to decrease heating temperature set points, is shown in Table 3. The respondents were willing or slightly willing to turn off their heating or air-conditioning for a short time when electricity price peaks. On the other hand, respondents had a slightly lower willingness to reduce the room temperature during high electricity price periods. This might be because temperature is a word that is more directly related to thermal sensations. Some respondents commented, "My wife and I always prefer to have a

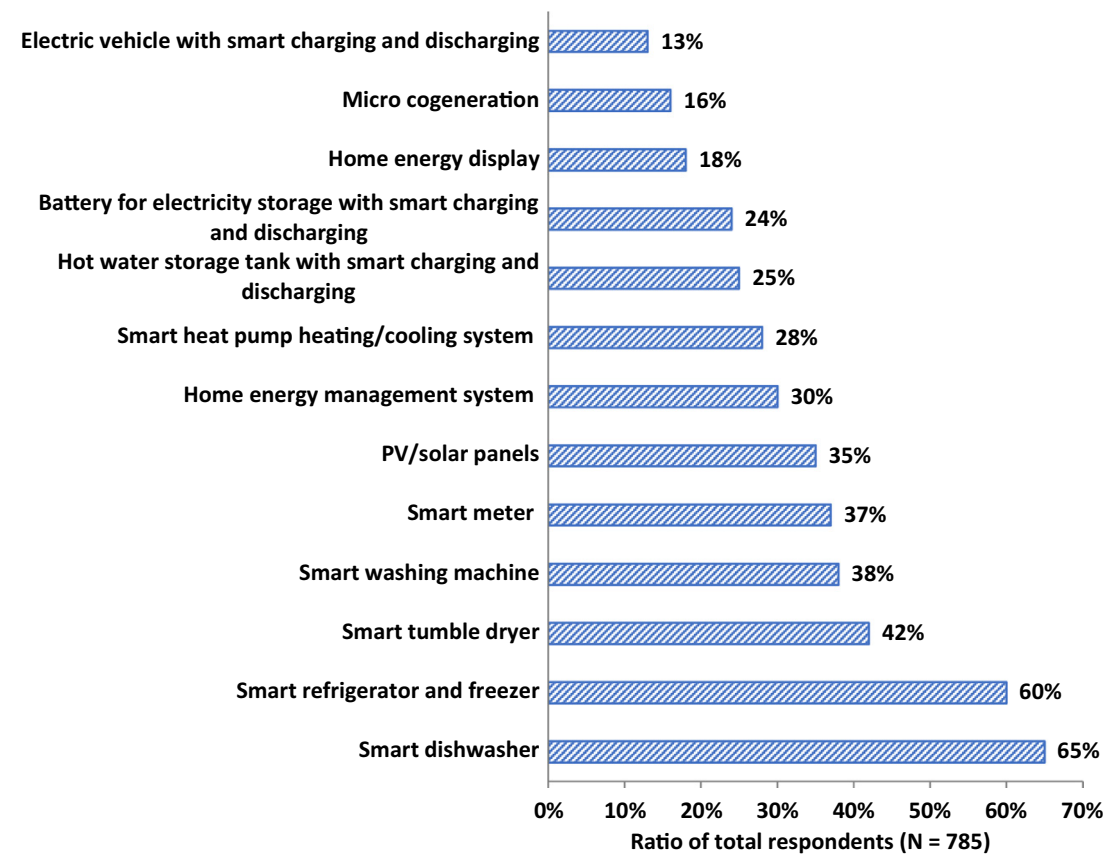

Fig. 6. Willingness to use smart technologies. 
Table 2

Willingness to postpone smart appliance start time.

\begin{tabular}{|c|c|c|c|c|c|}
\hline \multirow[t]{2}{*}{ Appliance } & \multirow{2}{*}{$\begin{array}{l}\text { Unwilling } \\
0 \mathrm{~h}\end{array}$} & \multicolumn{4}{|l|}{ Willing } \\
\hline & & $20 \mathrm{~min}^{-1} \mathrm{~h}$ & $1-4 \mathrm{~h}$ & $4-8 \mathrm{~h}$ & Any time within $24 \mathrm{~h}$ \\
\hline Dishwasher & $15 \%$ & $18 \%$ & $15 \%$ & $10 \%$ & $43 \%$ \\
\hline Tumble dryer & $23 \%$ & $16 \%$ & $16 \%$ & $12 \%$ & $35 \%$ \\
\hline Washing machine & $25 \%$ & $17 \%$ & $13 \%$ & $7 \%$ & $28 \%$ \\
\hline Iron & $41 \%$ & $19 \%$ & $9 \%$ & $6 \%$ & $25 \%$ \\
\hline Vacuum cleaner & $42 \%$ & $20 \%$ & $10 \%$ & $6 \%$ & $21 \%$ \\
\hline Heating system & $45 \%$ & $26 \%$ & $7 \%$ & $5 \%$ & $16 \%$ \\
\hline Electric vehicle (charging battery) & $46 \%$ & $15 \%$ & $10 \%$ & $5 \%$ & $24 \%$ \\
\hline Oven & $52 \%$ & $23 \%$ & $7 \%$ & $3 \%$ & $14 \%$ \\
\hline
\end{tabular}

Table 3

Behaviour change potential ( 1 = "strongly willing", 2 = "willing", 3 = "slightly willing", 4 = "unwilling", 5 = "I do not care").

\begin{tabular}{lll}
\hline Behaviour change & Mean & $\sigma$ \\
\hline $\begin{array}{l}\text { Willingness to turn off the heating or air-conditioning } \\
\text { system for a short time when energy price peaks }\end{array}$ & 2.59 & 1.04 \\
$\begin{array}{l}\text { Willingness to reduce the room temperature setting } \\
\text { for the heating system when energy is expensive }\end{array}$ & 3.03 & 1.26 \\
\hline
\end{tabular}

$\sigma:$ Standard deviation.

warm living room during the long winter," indicating that heating systems are an important aspect of comfortable living. It could be hard for some of the respondents to imagine that a slightly lower temperature setting might not affect their comfort. A study in Denmark discovered that two degrees of temperature variation was accepted by occupants [31]. Further research in the Netherlands should focus on field tests to evaluate the effect of short duration temperature changes on the thermal comfort of Dutch residents. Real time indoor temperature displays should be provided for residents in their home energy displays or by other means.

\subsubsection{Preferred control options}

Dynamic energy pricing is assumed to be the key factor that stimulates active control over appliances. Possible control options with their availability and potential economic benefit were described as follows:

You can reduce your energy bill using the following three control options. (1) You can check the hourly energy price on your home energy display and manually control your appliances based on your own decision (called manual control). However, this will only yield a small energy bill reduction. (2) Your home energy management system can automatically turn your appliances on or off based on your preferences and the hourly energy prices received from your energy suppliers (called home automatic control). This involves you being partly in control and still reduces your energy bill by a medium amount. (3) You can set the final finishing time for your appliances and let your electricity supplier remotely control the start time of your appliances (called grid remote control). This control can generate relatively high savings on your energy bill.

In this study, grid remote control (also called direct load control) by the utility and home automatic control via home energy management systems were considered as possible solutions. Fig. 7 shows respondent preferences for control options. For each appliance, the preferred control was either grid remote control or home automatic control. On average for all technologies, half of the respondents stated that they preferred one of these two options. This result is in line with a finding in a Danish study of heat pumps that heat pump owners are willing to let their heat pump be controlled when incentives are applied [33]. The willingness to accept non-manual control of their technologies was much higher in comparison to previous studies carried out in Portugal [34] and Great Britain [35]. In the Portuguese study [34], only the option of direct load control from the utility was given. With three options (remote control, automatic control, and switch from manual control to remote or automatic control) provided in this study, the willingness to accept non-manual control increased dramatically, with on average only a minority (33\%) of respondents preferring manual control or no control. This result indicates that user preferences for control options differ. Multiple control options should be considered and investigated in the development of smart technologies.

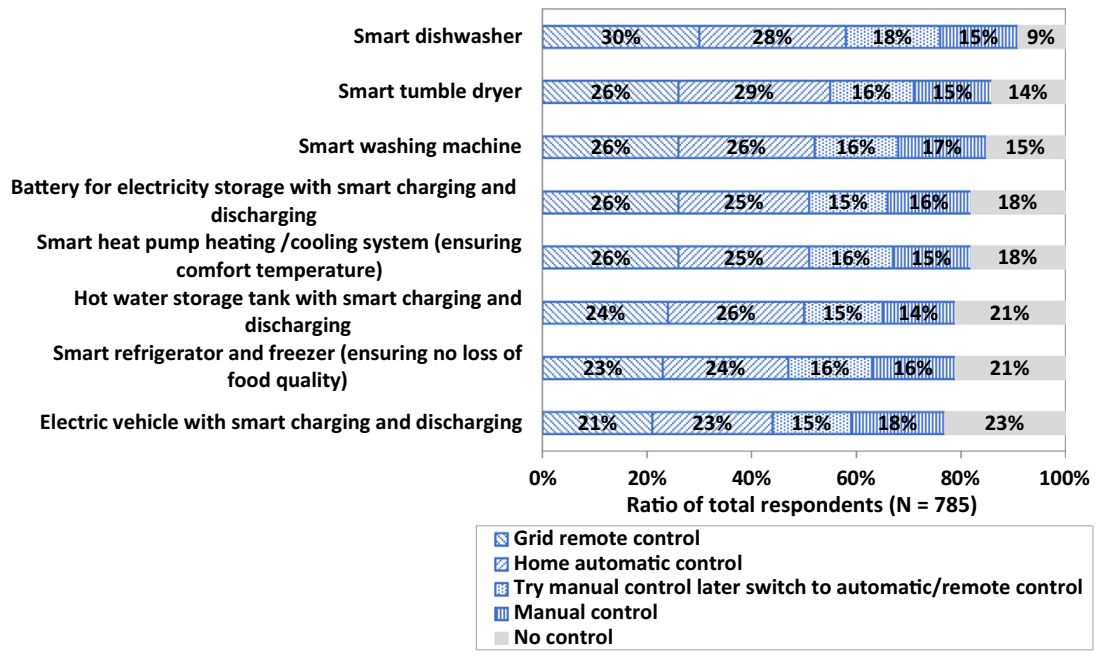

Fig. 7. Preference of control options. 
Table 4

Motivating factors ( 1 = "strongly motivating," 2 = "motivating," 3 = "slightly motivating," 4 = "not motivating," and 5 = "I do not care").

\begin{tabular}{lll}
\hline Measure & Mean & $\sigma$ \\
\hline Reducing energy bill & 1.91 & 1.11 \\
Receiving a financial reward from your energy supplier & 2.04 & 1.13 \\
Seeing the effects of your energy use actions & 2.24 & 1.12 \\
Reducing $\mathrm{CO}_{2}$ emissions & 2.36 & 1.12 \\
Being acknowledged for your efforts & 2.41 & 1.25 \\
Being flexible at using energy & 2.51 & 1.09 \\
Giving your house more sustainable character & 2.52 & 1.19 \\
$\quad$ (e.g., installed pv on the roof) & & \\
Contributing to reliability of the electricity grid & 2.57 & 1.11 \\
Making your house high-tech & 2.81 & 1.17 \\
Comparing with other households & 3.06 & 1.20 \\
Sharing your results on social media & 3.53 & 1.03 \\
\hline
\end{tabular}

$\sigma:$ Standard deviation.

The issues of privacy and control might be judged important by users, since information about energy usage patterns and energy consumption for their buildings would be collected via smart meters and sent to the electricity company. In a previous study, privacy issues were cited as one of the primary barriers to choosing remote or automatic control and accepting smart grid technologies [36]. However, this factor does not seem to have much impact for Dutch residents. In fact, privacy was only stated by $28 \%$ of the respondents to be an important factor in considering a smart appliance.

\subsubsection{Motivating factors for adopting smart technologies}

Previous research has discussed several factors that motivate users to adopt smart technologies in smart grids or smart homes [26,34,36-39]. Based on these studies, we developed eleven factors for our questionnaire and used a Likert scale with $1=$ "strongly motivating," 4= "not motivating," and 5= "I do not care" as choices. The results are shown in Table 4. Across all of the factors, the mean value was 2.54 , or motivating to slightly motivating. The two most motivating factors were reduced energy bills and financial rewards from the energy supplier. For these two factors, only 9 and $11 \%$, respectively, of respondents stated "not motivating" or "I do not care." One clearly not motivating factor was sharing the results on social media, with $51 \%$ of respondents choosing "not motivating" and $12 \%$ choosing "I do not care." Besides the financial benefits, other motivating factors included seeing the effects of their energy use actions, reducing $\mathrm{CO}_{2}$ emissions, and being acknowledged. This indicates that people expect to see the effects of their efforts and to be recognized for their contribution. These factors should be considered during product design, for instance by incorporating them into a home energy display, and into smart grid business model development.

\subsection{Identification of potential flexible building users based on statistical analysis}

In this section, the identification of potential flexible building users is presented based on the data shown in Section 3.1. Respondent willingness to use smart technologies and change their energy use behaviours were used as dependent variables in statistical analysis. The independent variables consisted of individual and household characteristics, dwelling characteristics, household energy usage, familiarity with smart grid technologies, and respondent energy attitudes. The correlation of these independent variables were checked prior to regression analyses and the results show that none of the variables are correlated with each other. I.e., the variables found to be significant in the regression analysis were independent of each other. Table 5 shows the results of these analyses. In the table, the values indicate the coefficients, and each significant coefficient is marked with an asterisk $\left(^{*}\right)$.

\subsubsection{Willingness to use smart technologies}

In the questionnaire, respondents were asked whether they would be willing to use each smart technology or not, and the results can be seen in Fig. 6. For the statistical analysis, we summed the number of smart products that each respondent would be willing to use. This summation gave us an overall score for each respondent. This overall score indicates the willingness of a respondent to use smart technologies in general. The higher the number of smart technologies that a respondent is willing to use, the more willing the respondent is to use smart technologies in general. Since this overall score is a continuous value, we used a linear regression. The results can be seen in Table 5 (column: Use ST). The adjusted R-square was found to be 0.164 . Young respondents, aged between 20 and 29 years old, were found to be significantly more willing to use smart technologies, which is also in line with the findings of their familiarity with smart grids. If the respondents were living in a dwelling that was less than $50 \mathrm{~m}^{2}$ in floor area, then they were less willing to use smart technologies. This might be due to low energy consumption or low income. In addition, if respondents did not know the impact of their energy bill on their household budget, they were more willing to use smart technologies. Compared to those with low energy bills, respondents paying energy bills between 100 and 150 Euro per month were found to be more willing to use smart technologies.

When we look at their attitudes, respondents who were more willing to temporarily reduce the set-point temperature of heating, postpone the start time of appliances, and use one of the control options were significantly more willing to use smart technologies.

\subsubsection{Willingness to postpone the start time of appliances}

In the questionnaire, respondents were asked for how long they would be willing to postpone the start time of each appliance, given that they would obtain some financial benefits. We assigned a score of one if they were willing to postpone an appliance at all, regardless of for how long, and cumulated their scores for all appliances. The total score was used in the statistical analysis. This score indicates the number of appliances that each respondent would be willing to postpone using. Since this score is a continuous variable, we used a linear regression to estimate the model. The adjusted Rsquare was found to be 0.309 .

The results indicate that middle income respondents were willing to postpone more appliances, compared to low income respondents. Moreover, respondents with energy bills between 100 and 200 Euro per month were willing to postpone more appliances compared to respondents paying less than 100 Euro per month. Using a heating system with a constant temperature setting was found to have a strong positive influence on the number of appliances that a respondent was willing to postpone using. In addition, using the heating only when someone is present was also found to have a positive effect on the number of appliances that respondents were willing to postpone using.

It was found that increasing familiarity with the smart grid increased the number of appliances that a respondent was willing to postpone using. When we looked at their attitudes, we saw that respondents that were willing to turn off heating or cooling for a short time were willing to postpone using a larger number of appliances. Lastly, people who were more willing to use one of the control options were more willing to postpone the start time of their appliances. 
Table 5

Aggregation analysis of user willingness.

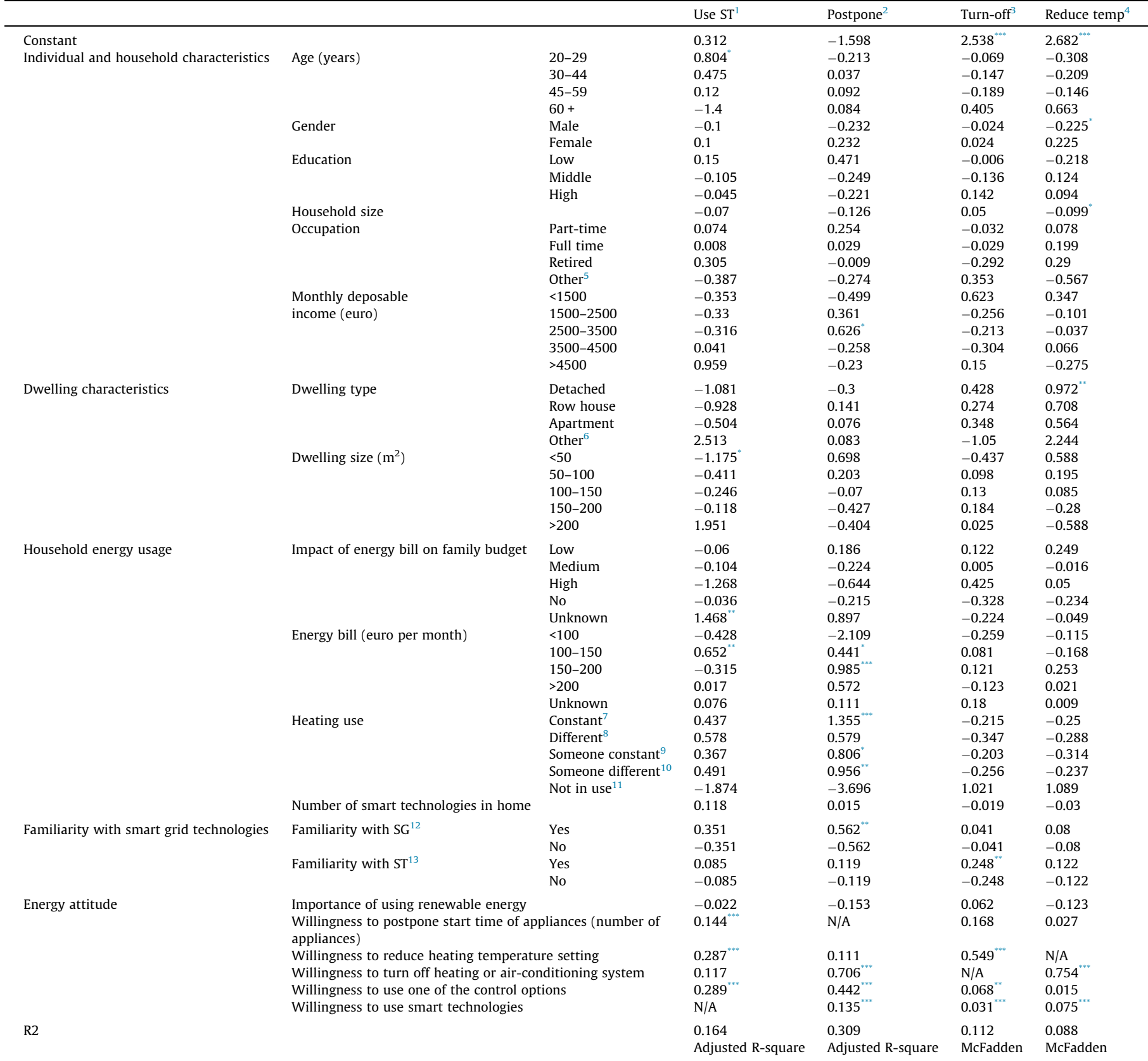

Note:

Significant at $1 \%$ level.

** Significant at 5\% level.

Significant at $10 \%$ level.

1 "Use ST" stands for the willingness to use smart technologies.

2 "Postpone" stands for the willingness to postpone the start time of appliances.

3 "Turn-off" stands for the willingness to turn off heating or air-conditioning for a short time.

4 "Reduce temp" stands for willingness to reduce the heating temperature setting.

5 "Other" includes students and unemployed.

6 "Other" includes a shared house or apartment and student dormitory.

7 "Constant" means that the heating system is always turned on at a constant temperature set-point.

8 Different" means that the heating system is always turned on, but has different temperature set-points for different times of the day.

9 "Someone constant" means that the heating system is turned on only when someone is at home at a constant temperature set-point.

10 "Someone different" means that the heating system is turned on only when someone is at home, and has different temperature set-points for different times of the day.

11 "Not in use" means that the heating system is not often used.

$12 \mathrm{SG}=$ smart grids.

$13 \mathrm{ST}=$ smart technologies. 


\subsubsection{Willingness to turn off heating or air-conditioning for a short time}

The respondents were asked how willing they would be to turn off their heating or air-conditioning system for a short time when the energy price peaked. They were given a 5 level Likert scale, from "strongly willing" to "I do not care" as described in Section 3.1.4. Since the dependent variable was ordinal, we conducted an ordinal regression analysis. The McFadden R-square was found to be 0.112 . In social sciences, $\mathrm{R}$-square around 0.20 is considered to indicate a good fit. Falk and Miller [40] recommended that Rsquare values should be equal to or greater than 0.10 in order to explain the variance adequately. Therefore, the results of this analysis are valid for obtaining insights into the willingness of respondents.

According to the results, no sociodemographic influences, dwelling characteristics, or energy bill related variables were found to be significant. Only familiarity and attitudinal effects were observed. If respondents were familiar with smart technologies, then they were more willing to turn off their heating or air-conditioning for a short time when energy price peaked. This finding is in line with some studies of knowledge and attitudes regarding energy savings in other countries, such as [41], and [42], in which correlation between knowledge and attitudes were identified.

Moreover, as the number of technologies that they were willing to use increased, their willingness to turn off their heating or airconditioning also increased. In addition, with an increase in willingness to reduce the heating temperature setting, the willingness to turn off heating or air-conditioning systems also increased. Finally, as the willingness to control smart technologies increased, willingness to turn off the heating or air-conditioning system also increased.

\subsubsection{Willingness to reduce heating temperature settings}

Respondents were asked how willing they would be to reduce the room temperature setting for their heating system when energy price peaked. This was measured by a 5-level Likert scale, with "strongly willing," “willing," "slightly willing," "unwilling," and "I don't care." Since the dependent variable was ordinal, we applied an ordinal logit regression analysis. The McFadden R-square was found to be 0.088 . Although this value is low, these results can be used for understanding the behaviour of respondents.

According to the results, male respondents were found to be less willing to reduce the temperature setting of the heating system compared to female respondents. Moreover, households with more members were less willing to reduce the heating temperature setting. Respondents living in detached houses were more willing to reduce the heating temperature setting compared to respondents living in other types of dwellings.

In the attitudinal effects, it can be seen that with an increase in the willingness to use smart technologies, the willingness to reduce the heating temperature setting when energy price peaks also increased. Finally, we found that, with an increase in the willingness of respondents to turn off heating or air-conditioning, their willingness to reduce the temperature setting of the heating system when energy was expensive also increased.

\subsubsection{Potential flexible building users}

The statistical analysis shows that some individual, household, and dwelling characteristics, such as age, gender, house type, house size, household size, and income, influence willingness to adopt some smart grid technologies. However, these variables were not found to have a significant impact on overall willingness. These results therefore do not allow us to make generalized conclusions regarding the identification of population groups in terms of their readiness for energy flexible buildings. The reason could be that smart grids and their related technologies are in general unfa-

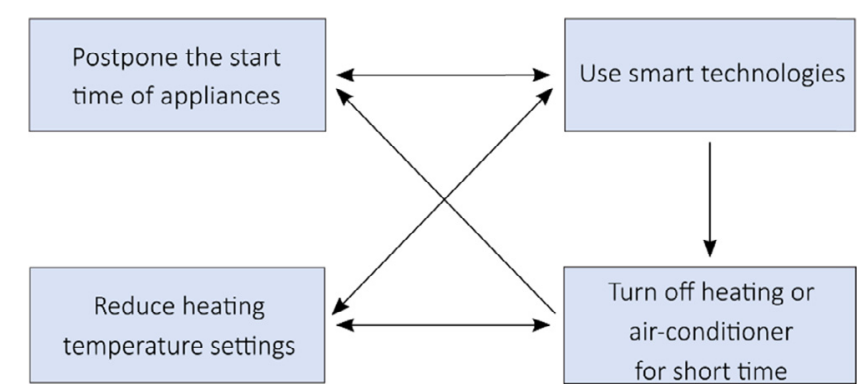

Fig. 8. Interdependencies found among four measures of willingness to adopt smart technologies.

miliar to the population. This is different from other studies of user perception of energy conservation in dwellings, such as Hara et al. [43]. Their study based on a large-scale survey in Japan found that family size, age, household income and number of air conditioners are determinant factors of the respondents' perception of household energy conservation. We believe this can be explained by building energy conservation being a familiar topic to residents while smart grids and energy flexible buildings are not.

Furthermore, we find that household energy attributes, such as the average energy bill, the impact of the energy bill on the family budget, and their habitual usage of heating systems all influenced their willingness to adopt smart grid technologies. These influences were more marked for willingness to postpone the start of home appliances and to use smart technologies. In addition, increasing familiarity with smart grid technology also increased willingness to change energy use behaviour, as expected.

When we look at the attitudinal variables, we can see that there was an interdependency between the variables that define willingness to adopt smart grid technology (as illustrated in Fig. 8): (1) people who are willing to postpone the start of home appliances are also willing to use smart technologies and vice versa; (2) people who are willing to use smart technologies are also willing to turn off heating or air-conditioning for a short time and to reduce the heating temperature setting; (3) people who are willing to turn off heating or air-conditioning for a short time are also willing to reduce the heating temperature setting and vice versa.

According to these results, we define potential flexible building users as those who are willing to use smart technologies and change their energy use behaviours, including postponing the start of appliances, turning off heating or cooling for a short time, and reducing the heating temperature setting. To estimate the number of potential flexible building users, we assume that flexible building users are:

- willing to postpone the start time of half or more of their appliances,

- willing to use half or more of the smart technologies listed in the questionnaire,

- willing to turn off their heating or air-conditioning, and

- willing to reduce the heating temperature setting.

Based on this assumption, we found that $11 \%$ of the respondents were potential flexible building users. Although this value is somewhat arbitrary and dependent on the above criteria, it gives a rough understanding of the readiness of inhabitants for energy flexible buildings.

\section{Conclusions}

This paper presented the investigation of the readiness of building users on energy flexible buildings, an area that has not been 
greatly explored in existing literature. A large-scale survey with usable results from 785 respondents was conducted in the Netherlands to investigate residential building occupants' perceptions of smart grid technologies and their readiness to use energy flexible buildings. The survey respondents were representative of the Dutch population based on comparison with data from the Central Bureau of Statistics in the Netherlands. According to a descriptive analysis, more than $60 \%$ of the respondents were unaware of smart grids. However, young respondents were more aware of smart grids than older respondents. The two smart technologies that respondents were most willing to use were smart dishwashers (65\%) and smart refrigerator/freezers (60\%). A majority of the respondents were willing to change their energy use behaviour, including turning off their heating or air-conditioning for a short time, reducing the room temperature setting for the heating system, or postponing the start time of home appliances. For the control of smart technologies, a majority accepted one of the four control options: grid remote control, home automatic control, manual control, and try manual control first later switch to grid remote control or home automatic control. The level of acceptance was much higher than has been found in other studies. This result indicates that multiple control options should be included in the development of smart technologies to achieve high user acceptance and therefore realize the energy flexibility of home appliances. The top three motivating factors for users adopting smart technologies were found to be: reduced energy bills (strongly motivating), financial rewards from the energy supplier (motivating), and seeing the effects of energy use actions (motivating).

The regression analysis indicated that young people (2029 years old) were more willing to use smart technologies. We also found that household energy consumption, in terms of the average monthly energy bill (100-200 Euro) and heating system usage (keeping heating constantly on) influences the willingness of users to adopt smart grid technology. This might be due to the monetary considerations of people regarding their electricity and heating expenditures. Moreover, increasing familiarity with smart grid technology had a positive influence on the willingness to change energy use behaviours. These analyses also reveal interdependency between variables that determine willingness to adopt smart technologies and changing energy use behaviours. Accordingly, we defined potential flexible building users as those who are willing to use smart technologies and change their energy use behaviours, including turning off heating or air-conditioning for a short time, reducing the heating temperature setting, and postponing the start times for their home appliances. With certain assumptions, $11 \%$ of the respondents were found to be potential flexible building users.

These results obtained from the study provide important insights for energy policy and energy companies to make policies and strategies towards the development of future power grid and encouraging building users to be more flexible. For example, in order to encourage people to adopt smart grid technology, awareness of smart grids must be increased. Awareness should not be limited to young people, but should be disseminated to the entire population. The adoption of smart grids can also be increased through financial incentives by focusing on residents with midlevel energy bills. It appears that people who are willing to use smart technologies are also willing to change their energy use behaviour, and can thus be defined as flexible. In order to unlock building energy flexibility, the adoption of smart technologies should be encouraged by providing incentives such as financial rewards.

\section{Acknowledgements}

This work is part of the research activities of the International Energy Agency-Energy in Buildings and Communities Program Annex 67, Energy Flexible Buildings. The authors thank Annex 67 colleagues Anne Stafford, Søren Østergaard Jensen, Roberta Pernetti and Erwin Mlecnik for reviewing this paper prior to submission.

\section{Appendix A}

See Table A1.

Table A1

Questions in the survey.

\begin{tabular}{|c|c|}
\hline Aspects & Questions \\
\hline $\begin{array}{l}\text { Individual and household } \\
\text { characteristics }\end{array}$ & $\begin{array}{l}\text { Age, gender, education level (primary school or lower, high school, technical high school, university, postgraduate), household size, } \\
\text { occupation (student, part-time work, full-time work, self-employed, un-employed, retired), household monthly deposable income }\end{array}$ \\
\hline Dwelling characteristics & $\begin{array}{l}\text { Dwelling type (detached/semi-detached house, row house, apartment building, student dormitory, shared house or apartment), } \\
\text { dwelling size (less than } 50 \mathrm{~m}^{2}, 50-100 \mathrm{~m}^{2}, 100-150 \mathrm{~m}^{2}, 150-200 \mathrm{~m}^{2} \text {, more than } 200 \mathrm{~m}^{2} \text { ) }\end{array}$ \\
\hline \multirow[t]{3}{*}{ Household energy usage } & $\begin{array}{l}\text { What impact does the energy bill have on your household budget? (very high impact, high impact, medium impact, low impact, no } \\
\text { impact, I don't know) }\end{array}$ \\
\hline & $\begin{array}{l}\text { How much is your household average energy bill (electricity and gas) per month? (€50 or less, } € 50-€ 100, € 100-€ 150, € 150-€ 200, € 200 \\
\text { or more, I don't know) }\end{array}$ \\
\hline & $\begin{array}{l}\text { How does your household use the heating system? (always turned on at a constant temperature set-point, always turned on but has } \\
\text { different temperature set-points for different times of the day, turned on only when someone is at home at a constant temperature set- } \\
\text { point, turned on only when someone is at home and has different temperature set-points for different times of the day, not often used) }\end{array}$ \\
\hline \multirow[t]{2}{*}{$\begin{array}{l}\text { Familiarity with smart grid } \\
\text { technologies }\end{array}$} & $\begin{array}{l}\text { How familiar were you with the concept of smart grids before this questionnaire? (never heard of it, heard a little of it but don't } \\
\text { understand the concept, heard a lot of it but don't understand the concept, know a little about the concept, know a lot about the } \\
\text { concept) }\end{array}$ \\
\hline & $\begin{array}{l}\text { How familiar are you with the following smart home appliances and energy control systems? - smart washing machine, smart tumble } \\
\text { dryer, smart dishwasher, smart refrigerator/freezer, smart heat pump heating/cooling system, hot water storage tank with smart charging and } \\
\text { discharging, battery for electricity storage with smart charging and discharging, electric vehicle with smart charging and discharging, pv/solar } \\
\text { panels, micro co-generation (micro combined heat and power), smart meter, home energy management system, home energy display - (never } \\
\text { heard of it, heard of it but do not understand the concept, know a little about the concept, know a lot about the concept, I own one) }\end{array}$ \\
\hline \multirow[t]{2}{*}{ Energy attitude } & $\begin{array}{l}\text { How important is it to save energy and use renewable energy in your house? (very important, important, slightly important, } \\
\text { unimportant, very unimportant) }\end{array}$ \\
\hline & $\begin{array}{l}\text { Which of the following appliances/systems would you like to use? (please select all those that apply - smart washing machine, smart } \\
\text { tumble dryer, smart dishwasher, smart refrigerator/freezer, smart heat pump heating/cooling system, hot water storage tank with smart } \\
\text { charging and discharging, battery for electricity storage with smart charging and discharging, electric vehicle with smart charging and } \\
\text { discharging, pv/solar panels, micro co-generation (micro combined heat and power), smart meter, home energy management system, home } \\
\text { energy display) }\end{array}$ \\
\hline
\end{tabular}


Table A1 (continued)

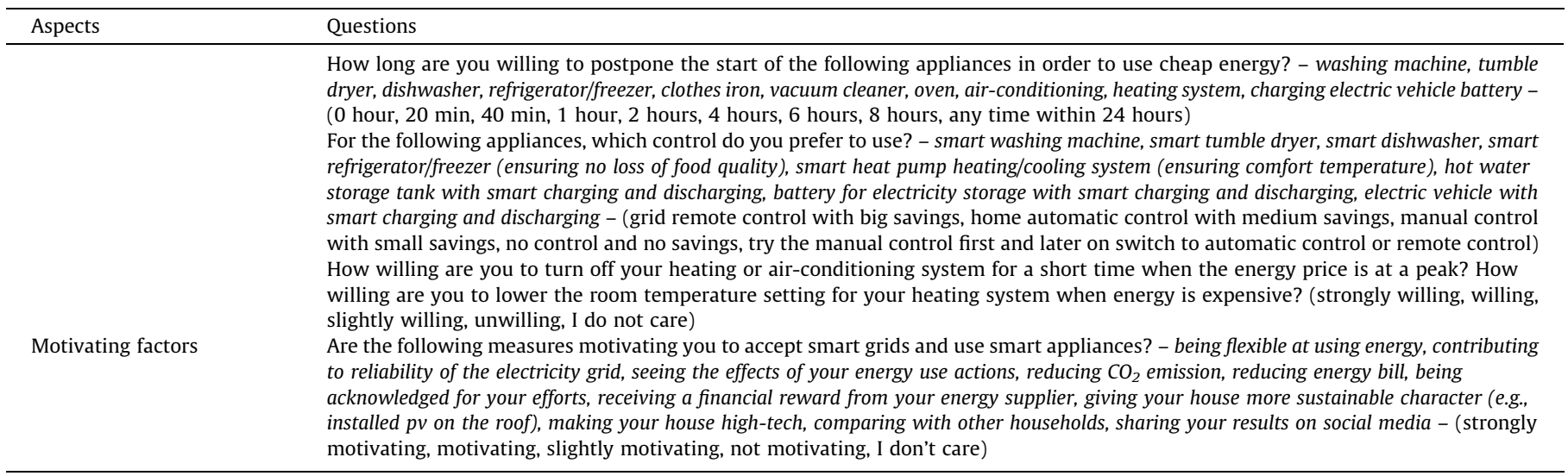

\section{References}

[1] Colak I, Fulli G, Sagiroglu S, Yesilbudak M, Covrig CF. Smart grid projects in Europe: current status, maturity and future scenarios. Appl Energy 2015;152:58-70.

[2] Lund PD, Lindgren J, Mikkola J, Salpakari J. Review of energy system flexibility measures to enable high levels of variable renewable electricity. Renew Sustain Energy Rev 2015;45:785-807.

[3] Vassileva I, Dahlquist E, Wallin F, Campillo J. Energy consumption feedback devices' impact evaluation on domestic energy use. Appl Energy 2013;106:314-20.

[4] Verbong G, Beemsterboer S, Sengers F. Smart grids or smart users? Involving users in developing a low carbon electricity economy. Energy Policy 2013;52:117-25.

[5] D’hulst R, Labeeuw W, Beusen B, Claessens S, Deconinck G, Vanthournout K. Demand response flexibility and flexibility potential of residential smart appliances: Experiences from large pilot test in Belgium. Appl Energy 2015;155:79-90.

[6] Kobus C, Klaassen E, Mugge R, Schoormans J. A real-life assessment on the effect of smart appliances for shifting households' electricity demand. Appl Energy 2015;147:335-43.

[7] Stamminger R, Anstett V. The effect of variable electricity tariffs in the household on usage of household appliances. Smart Grid Renew Energy 2013;4:353-65.

[8] Reynders G, Nuytten T, Saelens D. Potential of structural thermal mass for demand-side management in dwellings. Build Environ 2013;64:187-99.

[9] Masy G, Georges E, Verhelst C, Lemort V, André P. Smart grid energy flexible buildings through the use of heat pumps and building thermal mass as energy storage in the Belgian context. Sci Technol Built Environ 2015;21:800-11.

[10] Le Dréau J, Heiselberg P. Energy flexibility of residential buildings using short term heat storage in the therml mass. Energy 2016;111:991-1002.

[11] De Coninck R, Helsen L. Quantification of flexibility in buildings by cost curves - methodology and application. Appl Energy 2016;162:653-65.

[12] Vanthournout K, Dhulst R, Geysen D, Jacobs G. A smart domestic hot water buffer. IEEE Trans Smart Grid 2012;3:2121-7.

[13] Kensby J, Trüschel A, Dalenbäck JO. Potential of residential buildings as thermal energy storage in district heating systems - results from a pilot test. Appl Energy 2015;137:773-81.

[14] Hammerstrom DJ, Ambrosio R, Brous J, Carlon TA, et al., Pacific Northwest GridWiseTM Testbed Demonstration Projects Part I: Olympic Peninsula Project. 2007. https://www.smartgrid.gov/files/Pacific_Northwest_GridWise_ Testbed_Demonstration_Projects_Pa_200702.pdf [accessed 12.05.2017]

[15] Kok, Widergren. A society of devices. IEEE Power Energ Mag 2016;14:34-45.

[16] Kobus C. A switch by design - User-centered design of smart energy technologies to change habits of using energy at home. PhD thesis; 2016. p. 79-102 http://atriensis.nl/_userdata/files/Proefschrift_Publish(1).pdf [accessed 15.11.2016]

[17] Ippolito MG, Riva Sanseverino E, Zizzo G. Impact of building automation control systems and technical building management systems on the energy performance class of residential buildings: an Italian case study. Energy Build 2014;69:33-40.

[18] Graditi G, Ippolito MG, Lamedica R, Piccolo A, Ruvio A, Santini E, Siano P, Zizzo G. Innovative control logics for a rational utilization of electric loads and airconditioning systems in a residential building. Energy Build 2015;102:1-17.

[19] Ding Y, Pineda S, Nyeng P, Østergaard J, Larsen EM, Wu O. Real-time market concept architecture for EcoGrid EU-A prototype for European smart grids. IEEE Trans Smart Grid 2013;4:2006-16.

[20] Ayodele TR, Ogunjuyigbe ASO, Atiba IA. Assessment of the impact of information feedback of prepaid meter on energy consumption of city residential buildings using bottom-up load modeling approach. Sustain Cities Soci 2017;30:171-83.

[21] Geelen D, Reinders A, Keyson D. Empowering the user in smart grids: recommendations for the design of products and services. Energy Policy 2013;61:151-61.

[22] Obinna U, Joore P, Wauben L, Reinders A. Insights from stakeholders of five residential smart grid pilot projects in the Netherlands. Smart Grid Renew Energy 2016;7:1-15.

[23] Giordano V, Meletiou A, Covrig CF, Mengolini A, et al., Smart Grid projects in Europe: Lessons learned and current developments. JRC Scientific and Policy Reports; 2013. https://ses.jrc.ec.europa.eu/sites/ses.jrc.ec.europa.eu/files/ publications/ld-na-25815-en-n_final_online_version_april_15_smart_grid_ projects_in_europe_-_lessons_learned_and_current_developments_-2012_ update.pdf [accessed 12.05.2017]

[24] Scott F, Jones C, Webb T. What do people living in deprived communities in the UK think about household energy efficiency interventions? Energy Policy 2014;66:335-49.

[25] Sovacool BK, Blyth PL. Energy and environmental attitudes in the green state of Denmark: implications for energy democracy, low carbon transitions, and energy literacy. Environ Sci Policy 2015;54:304-15.

[26] Toft M, Schuitema G, Thøgersen J. Responsible technology acceptance: model development and application to consumer acceptance of Smart Grid technology. Appl Energy 2014;134:392-400.

[27] Kok K, Roossien B, MacDougall P, van Pruissen O, Venekamp G, Kamphuis R, Laarakkers J, Warmer C. Dynamic pricing by scalable energy management systems-field experiences and simulation results using PowerMatcher. IEEE PES General meeting; 2012.

[28] Faruqui A, Sergici S. Household response to dynamic pricing of electricity - a survey of the experimental evidence; 2009. https://www.hks.harvard.edu/ hepg/Papers/2009/The\%20Power\%20of\%20Experimentation\%20_01-11-09_.pdf [accessed 12.05.2017]

[29] Vanthournout K, Dupont B, Foubert W, Stuckens C, Claessens S. An automated residential demand response pilot experiment, based on day-ahead dynamic pricing. Appl Energy 2015;155:195-203.

[30] CBS, 2016. https://www.cbs.nl/en-gb/figures [accessed 28.09. 2016]

[31] COWI. Consumer preferences for temperature variations. Internal report. Cited in [Innovation toolbox: personas - know your customers, by Danish Technological Institute]; 2013.

[32] International Energy Agency. Technology roadmap smart grids, https://www. iea.org/publications/freepublications/publication/smartgrids_roadmap.pdf; 2011. accessed 25.11.2016.

[33] DONG Energy. DONG Energy Eldistribution A/S. The eFlex project. Report; 2012. http://www.antropologerne.com/assets/The-eFlex-Project-Main-ReportDONG-Energy.pdf [accessed 12.12.2016]

[34] Lopes M, Antunes CH, Janda KB, Peixoto P, Martins N. The potential of energy behaviours in a smart(er) grid: policy implications from a Portuguese exploratory study. Energy Policy 2016;90:233-45.

[35] Fell MJ, Shipworth D, Huebner GM, Elwell CA. Public acceptability of domestic demand-side response in Great Britain: the role of automation and direct load control. Energy Res Soc Sci 2015;9:72-84.

[36] Wilson C, Hargreaves T, Hauxwell-Baldwin R. Smart houses and their users: a systematic analysis and key challenges. Pers Ubiquit Comput 2015;19: 463-76.

[37] Maréchal K, Holzemer L. Getting a (sustainable) grip on energy consumption: The importance of household dynamics and 'habitual practices'. Energy Res Social Sci 2015;10:228-39.

[38] Niesten E, Alkemade F. How is value created and captured in smart grids? A review of the literature and an analysis of pilot projects. Renew Sustain Energy Rev 2016;53:629-38. 
[39] Paetz AG, Dütschke E, Fichtner W. Smart homes as a means to sustainable energy consumption: a study of consumer perceptions. J Consum Policy 2012;35:23-41.

[40] Falk RF, Miller NB. A primer for soft modeling. Akron, Ohio: University of Akron Press; 1992.

[41] Polonsky MJ, Vocino A, Grau SL, Garma R, Ferdous AS. The impact of general and carbon related environmental knowledge on attitudes and behaviour of US consumers. J Market Manage 2012;28:238-63.
[42] Flamm B. The impacts of environmental knowledge and attitudes on vehicle ownership and use. Transport Res Part D: Transport Environ 2009:14:272-9.

[43] Hara K, Uwasu M, Kishita Y, Tkeda H. Determinant factors of residential consumption and perception of energy conservation: time-series analysis by large-scale questionnaire in Suita, Japan. Energy Policy 2015;87:240-9. 